\title{
INFLUÊNCIA DE DIFERENTES NÍVEIS DE SOMBREAMENTO NO COMPORTAMENTO FISIOLÓGICO DE CULTIVARES DE CAFÉ (Coffea arabica L.) ${ }^{1}$
}

\author{
RUPERT BARROS DE FREITAS ${ }^{2}$ \\ LUIZ EDSON MOTA DE OLIVIERA ${ }^{3}$ \\ NELSON DELÚ FILHO ${ }^{3}$ \\ ANGELA MARIA SOARES ${ }^{4}$
}

\begin{abstract}
RESUMO - Realizou-se este trabalho com o objetivo de verificar o comportamento das cultivares de café Acaiá MG 474/19, Catuaí MG 99, Icatu Amarelo MG 3282 e Rubi MG 1192, com relação às características potencial hídrico, transpiração, temperatura da superfície foliar, condutância estomática, fotossíntese, concentração interna de carbono e eficiência fotoquímica do PSII, quando submetidos a níveis de sombreamentos de $30 \%, 50 \%, 70 \%$ e a pleno sol. As avaliações foram rea-
\end{abstract}

lizadas no Setor de Fisiologia Vegetal em mudas dessas cultivares. $\mathrm{O}$ delineamento experimental utilizado foi o inteiramente casualizado, sendo distribuídos três vasos por cultivar em cada tratamento. O potencial hídrico foliar não variou nas plantas nos diferentes tratamentos. A fotossíntese, condutância estomática, transpiração, eficiência fotoquímica do PSII apresentaram variações significativas em função dos níveis de sombreamento.

TERMOS PARA INDEXAÇÃO: Cafeeiro, sombreamento, fotossíntese, relações hídricas.

\section{INFLUENCE OF DIFFERENT SHADING LEVELS IN PHYSIOLOGICAL BEHAVIOR OF COFFEE CULTIVARS (Coffea arabica L.)}

\begin{abstract}
The objective of this work was to examine the coffee cultivars Acaiá MG 474/19, Catuaí MG 99, Icatu Amarelo MG 3282 and Rubi MG 1192, in relation to parameters such as water potencial, transpiration, leaf surface temperature, stomatic conductance, photosynthesis, internal carbon concentration and PSII photochemical efficiency when submitted to shading levels of 30,50 and $70 \%$ and full
\end{abstract}

sunlight. The evaluations were made in cuttings from these cultivars. The experimental design used was fully randomized with three pots for each treatment. The leaf water potential did not change according to treatments. The photosynthesis, stomatic conductance, transpiration and PSII photochemical efficiency showed significative variations in function of shading levels.

INDEX TERMS: Coffee tree, shading, photosynthesis, water relations.

\section{INTRODUÇÃO}

As cultivares recomendadas para o plantio em escala comercial apresentam elevado potencial econômico, que não tem sido explorado adequadamente pela maior parte dos cafeicultores, e para o estabelecimento e plantio, a escolha adequada é um fator que, sem dúvida, pode afetar mais a produtividade.

Apesar do grande número de espécies de café existentes, pouco se sabe sobre o potencial comercial que encerram e seu possível aproveitamento nos planos de melhoramento, sendo os países cafeicultores carentes de estudos comparativos (Fazuoli, 1986).

\footnotetext{
1. Parte da dissertação de mestrado do primeiro autor.

2. Engenheiro Agrônomo, MS em Fisiologia Vegetal, Departamento de Biologia da UNIVERSIDADE FEDERAL DE LAVRAS/UFLA, Caixa Postal 37 - 37200-000 - Lavras, MG.

3. Engenheiro Agrônomo, Professor do Departamento de Biologia/UFLA.

4. Bacharel em Física, Professora do Departamento de Biologia/UFLA.
} 
Vários processos fisiológicos são influenciados pela deficiência hídrica das plantas em períodos de seca, e a absorção da água do solo durante um período sem precipitação requer níveis de crescimento radicular até locais de maior umidade. Esse crescimento tem sido atribuído ao genótipo (O`Toole \& Bland, 1987) e ao ambiente (Nobel \& Lee, 1991), contribuindo para um maior particionamento da fitomassa para as raízes em função da parte aérea (Turner, 1986; Ludlon \& Muchow, 1990).

A interação entre a demanda evaporativa da atmosfera, potencial de água no solo, distribuição do sistema radicular e processos fisiológicos revela o estado energético de água na planta (Clark \& Hiler, 1973), e a expansão foliar, abertura estomática e outros processos associados à fotossíntese são diretamente afetados pela redução do potencial de turgescência da folha, pois a capacidade da planta em manter a turgescência foliar é uma grande adaptação ao déficit hídrico (Jones \& Turner, 1978).

Em sistemas agroflorestais, as espécies e cultivares consorciadas devem apresentar boa adaptação às condições edafoclimáticas locais e ao sombreamento promovido pelas seringueiras (Pereira et al., 1997); no cultivo de café adensado, essas condições também exercem um papel determinante em uma boa produção.

$\mathrm{O}$ cafeeiro pode ser conduzido em ambientes de baixa luminosidade, pois apresenta uma baixa irradiância de saturação, variando de 300 a $600 \mu \mathrm{molm}^{-2} \mathrm{~s}^{-1}$ (Kumar \& Tieszen, 1980; Fahl et al., 1994). Isso faz com que possa ser cultivado em sistemas mais sombreados, onde há predominância de baixa radiação.

Segundo Kumar \& Tieszen (1980), as altas taxas fotossintéticas foram encontradas sob moderada irradiância e, com 1200-1300 $\mu_{\text {molm }}{ }^{-2} \mathrm{~s}^{-1}$, não foram verificados danos no aparelho fotossintético. No entanto, radiações acima de $2200 \mu$ molm $^{-2} \mathrm{~s}^{-1}$, comuns em dias ensolarados das regiões tropicais, podem induzir à fotoinibição (Nunes et al., 1993).

Fahl \& Carelli (1994), estudando o efeito do sombreamento de 30,50 e $100 \%$ de luz solar em processos fisiológicos envolvidos na produção, avaliaram o crescimento (área foliar e altura), os teores de clorofila, nitrogênio total e a atividade da redutase do nitrato. Pelos resultados, constatou-se que 150 dias após o início do experimento, as diversas cultivares estudadas responderam diferentemente aos níveis de luz. A cultivar Apoatã C-3597 (C. canephora) apresentou o melhor desenvolvimento quando cultivada a $50 \%$ de luz, ao passo que as cultivares de $C$. arabica (Catuaí H 2077 2-5-81 e Mundo Novo LCP 388-17) não mostraram diferenças significativas no crescimento a 50 e $100 \%$ de luz. $\mathrm{O}$ sombreamento excessivo (30\% de luz) reduziu o desenvolvimento das cultivares de $C$. arabica, mas não alterou o de C. canephora, em relação ao cultivo a pleno sol. O crescimento da Icatu LC-3282 aumentou linearmente com os níveis de luz. O peso foliar específico diminuiu com o aumento do sombreamento em todas os cultivares estudadas.

Sondah et al. (1976) compararam as taxas fotossintéticas de espécies de $C$. arabica e $C$. canephora e constataram que as duas taxas fotossintéticas mais altas foram encontradas em plantas de $C$. arabica consideradas mais produtivas.

De acordo com Mazzafera \& Guerreiro Filho (1991), parece possível, a princípio, selecionar cafeeiros mais produtivos, com base nas taxas fotossintéticas de plantas no estádio inicial de desenvolvimento.

Campostrini (1994) realizou também estudos comparando fotossíntese e produtividade de cinco genótipos de café ( $C$. canephora), com baixa, média e alta produtividades, verificando que todos os genótipos apresentaram a mesma eficiência do aparelho fotossintético, demonstrando que a diferença em produtividade não está relacionada à capacidade fotossintética.

Objetivou-se no presente trabalho avaliar comparativamente a capacidade fotossintética, o potencial hídrico e a transpiração de plantas de diferentes cultivares de cafeeiros submetidos a diferentes intensidades de radiação solar.

\section{MATERIAL E MÉTODOS}

A seleção de cultivares para este estudo baseouse nas mais comercializadas na região, sendo obtidas mudas de sete meses de idade das cultivares Acaiá MG 474/19, Catuaí MG 99, Icatu Amarelo MG 3282 e Rubi MG 1192. Essas mudas foram colocadas num ambiente de $50 \%$ de radiação, permanecendo ali por um período de um mês, sendo, em seguida, transplantadas para colunas de pvc com aproximadamente $25 \mathrm{~cm}$ de diâmetro e contendo 16 litros de terra.

A partir do mês de junho, essas plantas foram colocadas em casa-de-vegetação, permanecendo nesse ambiente até o mês de novembro, quando foram levadas para telados com sombreamento de 70\%, 50\%, 30\% e a pleno sol, sendo aclimatadas por um período de um mês. Receberam água diariamente, buscando manter o solo próximo da capacidade de campo. No início das avaliações, pôde-se constatar a homogeneidade das plantas em cada tratamento recebido.

$\mathrm{O}$ delineamento experimental utilizado foi $\mathrm{o}$ inteiramente casualizado, sendo distribuídos três vasos 
por cultivar em cada tratamento. As plantas analisadas foram agrupadas em tamanhos semelhantes e, no dia 16/11/99, foram avaliados o potencial hídrico, densidade de fluxo de fótons fotossinteticamente ativos, transpiração, temperatura da superfície foliar, condutância estomática, fotossíntese e concentração interna de carbono.

O potencial hídrico foi avaliado no horário das $6 \mathrm{~h} 15$ às $6 \mathrm{~h} 45$ com o uso da bomba de pressão e as trocas gasosas, no horário de $11 \mathrm{~h} 30$ às $14 \mathrm{~h} 30$, com o IRGA-LCA4. Para as trocas gasosas, foram utilizadas, nas avaliações, as folhas localizadas no topo das plantas, totalmente iluminadas, sempre seguindo o caminhamento do sol no sentido leste/oeste. A eficiência fotoquímica do fotossistema II foi avaliada utilizando-se o fluorômetro PEA, nas mesmas folhas utilizadas nas avaliações de trocas gasosas.

\section{RESULTADOS E DISCUSSÃO}

Apesar de terem sido verificadas variações entre as cultivares para um mesmo nível de lumino- sidade, considerou-se que os resultados obtidos com o emprego de sombrites, com a intenção de provocar reduções gradativas na radiação solar disponível para as plantas, foram adequados para os propósitos deste trabalho. A temperatura foliar, dentro dos diferentes níveis de radiação recebidos pelos cultivares não variou ( $p>0,05)$, tendo as maiores temperaturas foliares ocorridas a pleno sol, seguidas do nível 30\% e $50 \%$ de sombra, e as menores com o maior sombreamento, de $70 \%$ ( $p>0,05)$ (Figura 1).

Na Figura 2 verifica-se que o nível de sombreamento de $70 \%$ apresentou as maiores taxas de fotossíntese, permanecendo com valores iguais nos níveis de 50\%, 30\% e decrescendo a pleno sol $(p<0,05)$, não verificando diferenças de fotossíntese entre as cultivares $(p>0,05)$. Os valores superiores no nível mais sombreado, com decréscimos a pleno sol, confirmam a afirmação de que temperaturas até $35^{\circ} \mathrm{C}$ favorecem a fotossíntese do cafeeiro e, acima desse valor, começam a provocar decréscimos.
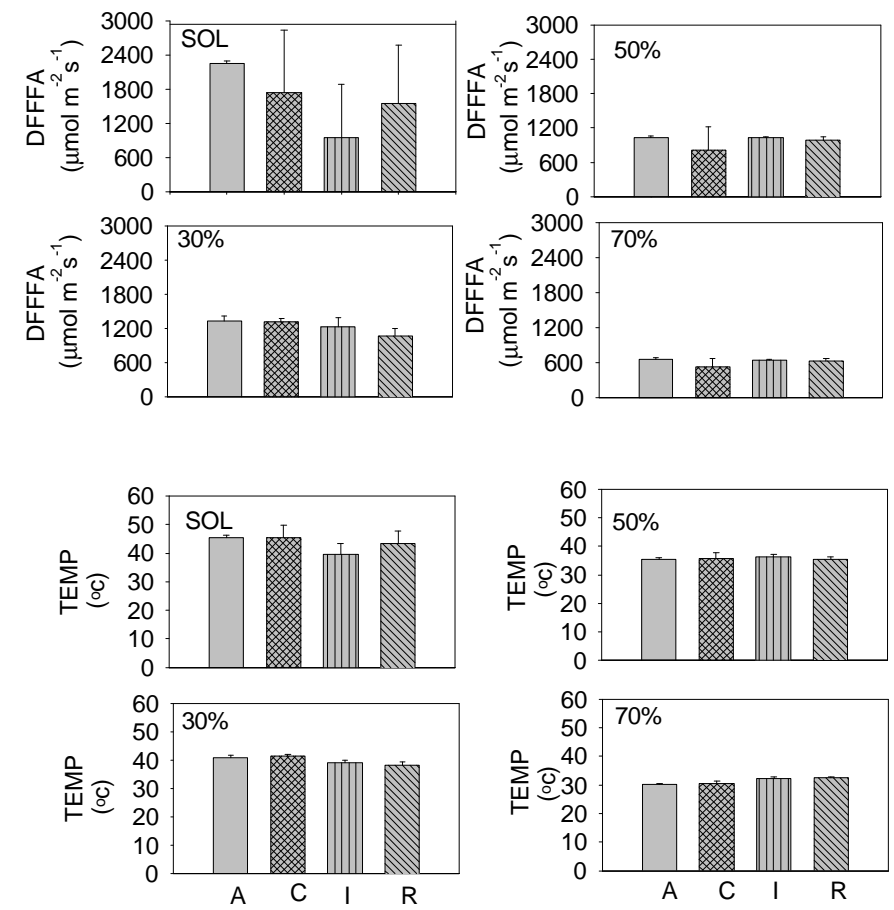

FIGURA 1 - Densidade de fluxo de fótons fotossinteticamente ativo (DFFFA) e temperatura foliar (TEMP) das cultivares Acaiá (A), Catuaí (C), Icatu(I) e Rubi(R) em função de diferentes níveis de sombreamento. As barras indicam o desvio-padrão da média de três plantas.

Ciênc. agrotec., Lavras. V.27, n.4, p.804-810, jul./ago., 2003 
Já a fluorescência apresentou diferenças em razão dos níveis de radiação, tendo valores mais baixos a pleno sol, quando ocorreram as maiores temperaturas $(\mathrm{p}<0,05)$, mas não entre as cultivares $(\mathrm{p}>0,05)$ em cada nível. A concentração interna de carbono variou $(\mathrm{p}<0,05)$, e as maiores taxas foram a pleno sol, seguindo $30 \%$ e $70 \%$ de sombra com os menores valores a $50 \%$ de sombreamento, ocorrendo diferenças entre as cultivares em cada nível, sem influenciar na fotossíntese de cada um.

As maiores taxas de condutância estomática e transpiração ocorreram a $70 \%$ de sombreamento e as menores, a pleno sol, observando-se que a cultivar Rubi apresentou as maiores condutâncias, tendo Icatu, Catuaí e Acaiá valores iguais $(\mathrm{p}<0,05)$, ocorrendo o mesmo para transpiração em relação a essas cultivares $(\mathrm{p}<0,05)$ (Figura 3). Sugere-se então que a cultivar Rubi apresenta um potencial maior em termos de condutância estomática e transpiração.

O déficit de pressão de vapor (Figura 4) variou entre as cultivares e nos diferentes níveis $(p<0,05)$, não tendo sido verificada a influência do mesmo nas cultivares, uma vez que tais variações foram mínimas.

Finalmente, a análise conjunta dos dados não nos permite inferir sobre uma possível produtividade diferencial entre as cultivares analisadas, pelo fato de esses estudos terem sido realizados com mudas. Entretanto, este estudo continuará sendo conduzido, pelo menos em condições de campo, até que se atinja a idade de produção, para uma análise final mais precisa.
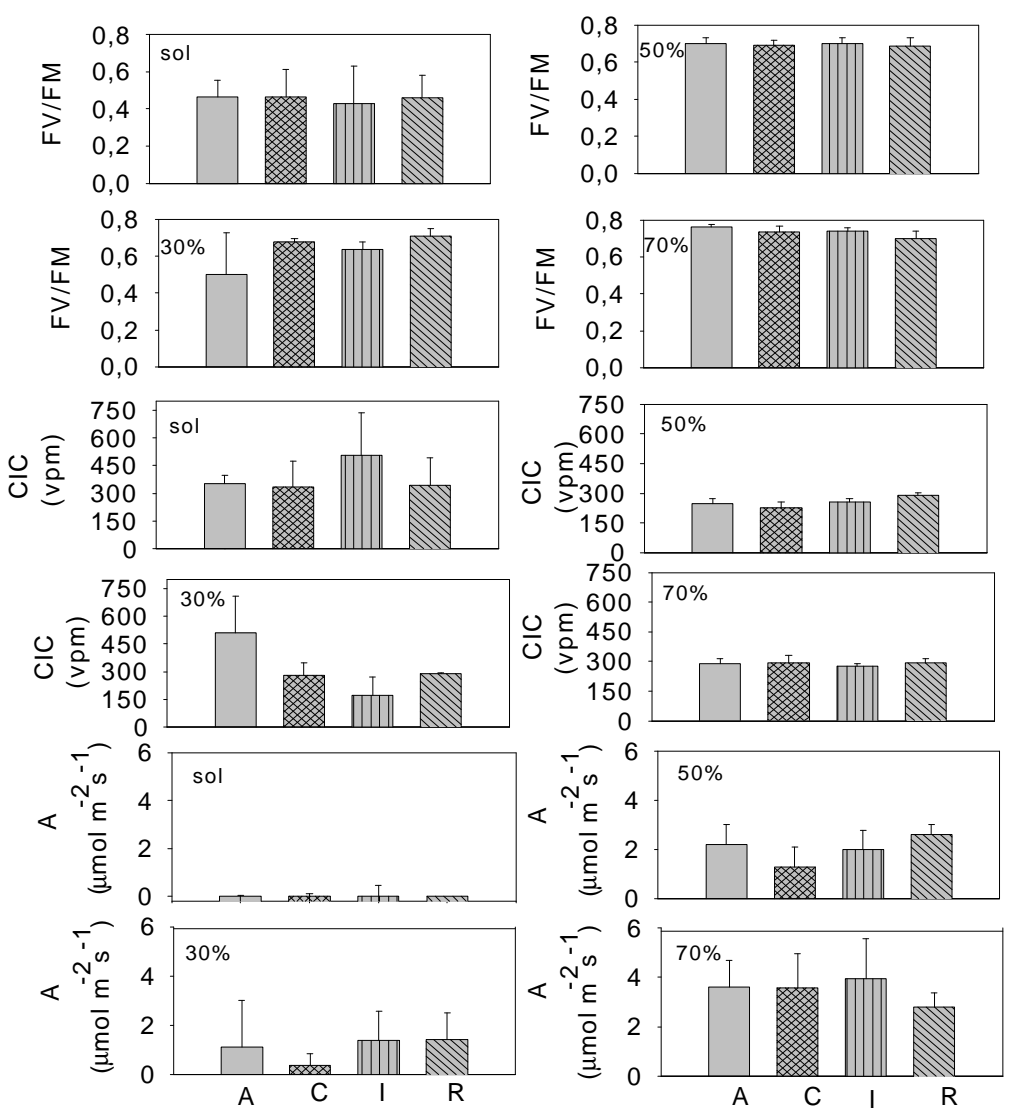

FIGURA 2 - Variação da fluorescência (FV/FM), concentração interna de carbono (CIC) e fotossíntese (A), das cultivares Acaiá (A), Catuaí (C), Icatu (I) e Rubi (R), em função de diferentes níveis de sombreamento. As barras indicam o desvio-padrão da média de três plantas. 

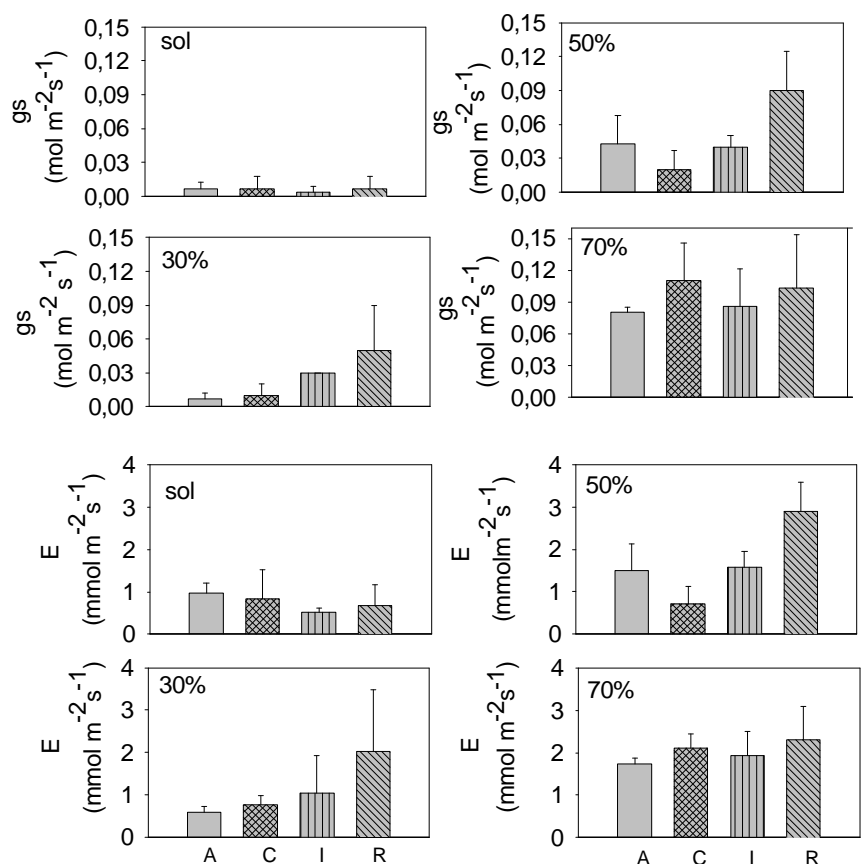

FIGURA 3 - Variação da condutância estomática (gs) e transpiração (E) das cultivares Acaiá (A), Catuaí (C), Icatu (I) e Rubi (R), em função de diferentes níveis de sombreamento. As barras indicam o desvio-padrão da média de três plantas.

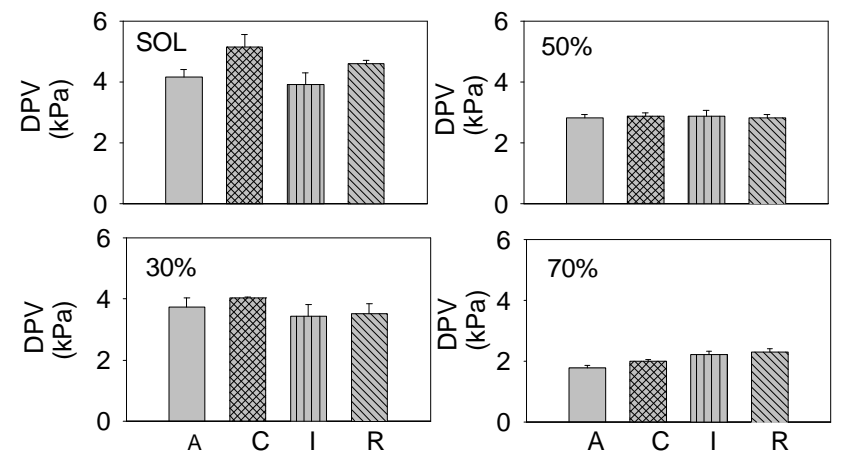

FIGURA 4 - Variação do déficit de pressão de vapor (DPV) das cultivares Acaiá (A), Catuaí (C), Icatu (I) e Rubi (R), em função de diferentes níveis de sombreamento. As barras indicam o desvio-padrão de três plantas.

Ciênc. agrotec., Lavras. V.27, n.4, p.804-810, jul./ago., 2003 


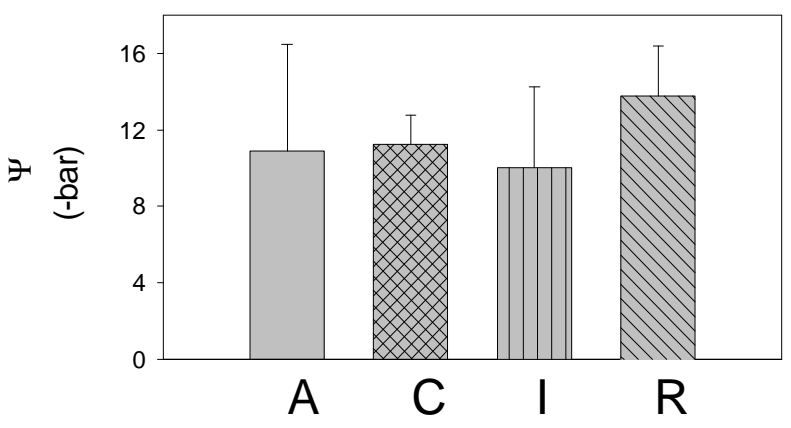

FIGURA 5 - Variação do potencial hídrico foliar ( $\Psi$ ) das cultivares Acaiá (A), Catuaí (C), Icatu (I) e Rubi (R), em função dos diferentes níveis de sombreamento. As barras indicam o desvio-padrão da média de três plantas.

\section{CONCLUSÕES}

Os sombrites empregados na redução da densidade de fluxo de fótons fotossinteticamente ativos foram efetivos.

As maiores e menores temperaturas foliares foram mantidas a pleno sol e a $70 \%$ de sombreamento, respectivamente.

Não foram observadas alterações significativas nos valores de potencial hídrico nas plantas avaliadas.

Todas as demais características avaliadas (concentração interna de carbono, fotossíntese, temperatura foliar, transpiração, fluorescência e déficit de pressão de vapor) apresentaram alterações significativas em função dos níveis de radiação.

\section{REFERÊNCIAS BIBLIOGRÁFICAS}

CAMPOSTRINI, E. Potencialidade fotossintética de cinco genótipos de Coffea Canephora Pierre. 1994. 40 f. Dissertação (Mestrado em Fisiologia Vegetal) - Universidade Federal de Viçosa, Viçosa, 1994

CLARK, R. N.; HILER, E. A. Plant measuements as indicators of crop water deficits. Crop Science, Madison, v. 13, n. 4, p. 466-9, July/Aug. 1973.

FAHL, J. I.; CARELLI, M. L. C. Influência do sombreamento nas características fisiológicas envolvidas no crescimento de espécies de coffea. In: SIMPÓSIO INTERNACIONAL SOBRE CAFÉ ADENSADO, 1994, Londrina. Anais... Londrina: IAP, 1994. p. 289290.
FAHL, J. I.; CARELlI, M. L. C.; VEGA, J.; MAGALHÃES, A. C. Nitrogen and irradiance levels affecting net photosynthesis and growth of young coffee plants (coffea arabica L.). Journal of Horticultural Science, Ashford, v. 69, p. 161-169, Jan. 1994.

FAZUOLI, L. C. Genética e melhoramento do cafeeiro. In: RENA, A. B.; MALAVOLTA, E.; ROCHA, M.; YAMADA, T. (Eds.). Cultura do cafeeiro: fatores que afetam a produtividade. Piracicaba: Associação Brasileira para Pesquisa da Potassa e do Fosfato, 1986. p. 87-106.

JONES, M. M.; TURNER, N. C. Osmotic adjustment in leaves of sorghum in response to water deficit. Plant Physiology, Maryland, v. 61, n. 1, p. 122-126, Jan. 1978.

KUMAR, D.; TIESZEN, L. L. Photosynthesis in Coffea arabica. I. Effects of light and temperature. Experimental Agriculture, Cambridge, v. 16, n. 1, p. 13-19, Jan. 1980.

LUDLON, M. M.; MUCHOW, R. C. A critical evaluation of traits for improving crop yields in water- limited environments. Advances in Agronomy, New York, v. 43, p. 107-53, 1990.

MAZZAFERA, P.; GUERREIRO FILHO, O. A produtividade do cafeeiro. Campinas: IAC, 1991. $21 \mathrm{p}$.

NOBEL, P. S.; LEE, C. H. Variations in root water potencials: influence of environmental factors for two succulent species. Annals of Botany, New York, v. 67, n. 6, p. 549-54, June 1991. 
NUNES, M. A.; RAMALHO, J. D. C.; DIAS, M. A. Effect of nitrogen supply on the photosynthetic performance of leaves from coffee plants exposed to bright light. Journal of Experimental Botany, Oxford, v. 44, n. 262, p. 893-899, May 1993.

O' TOOLE, J. C.; BLAND, W. L. Gentypic variation in crop plant root systems. Advances in Agronomy, New York, v. 41, p. 91-145, 1987.

PEREIRA, A. V.; PEREIRA, E. B. C.; FIALHO, J. de F.; JUNQUEIRA, N. T. V. Seringueira em sistemas agroflorestais. Planaltina: EMBRAPA/CPAC, 1997. 45 p. (EMBRAPA-CPAC. Documentos, 63).

SONDAHL, M. R.; CROCOMO, O. J.; SODEK, L. Measurements of ${ }^{14} \mathrm{C}$ incorporation by illuminated intact of coffee plants from gas mixtures containing ${ }^{14}$ $\mathrm{CO}_{2}$. Journal of Experimental Botany, Oxford, v. 27, n. 101 , p. 1187-1195, Dec. 1976.

TURNER, N. C. Crop water deficits: a decade of progress. Advances in Agronomy, New York, v. 39, p. 1$51,1986$. 